NASA Technical Memorandum 83619

\title{
Dual Clearance Squeeze Film Damper for High Load Conditions
}

David P. Fleming

Lewis Research Center

Cleveland, Ohio

Prepared for the

Joint Lubrication Conference

cosponsored by the American Society of Mechanical Engineers and the American Society of Lubrication Engineers

San Diego, California, October 22-24, 1984

\section{NRSA}




\title{
DUAL CLEARANCE SQUEEZE FILM DAMPER
}

\section{FOR HIGH LOAD CONDITIONS}

\author{
David P. Fleming \\ National Aeronautics and Space Administration \\ Lewis Research Center \\ Cleveland, Ohio 44135
}

\begin{abstract}
SUMMARY
Squeeze fllm dampers are widely used to control vibrations in aircraft turbine engines and other rotating machinery. However, if shaft unbalance rises appreclably above the design value (e.g., due to a turbine blade loss), a conventional squeeze film will be overloaded, and will no longer be effective in controlling vibration amplitudes and bearing forces. This paper describes $\dot{m}$ a new damper concept characterized by two $011 \mathrm{films}$. Under normal conditions, only one low-clearance $f 11 \mathrm{~m}$ is active, allowing precise location of the shaft centerline. Under high unbalance conditions, both films are active, controlling shaft vibration in a near-optimum manner, and allowing continued operation until a safe shutdown can be made.
\end{abstract}

\section{INTRODUCTION}

Squeeze film dampers have been used successfully for many years to control vibration of gas turbine rotors. Many aircraft engines depend on them to keep vibration from exceeding tolerable levels. Conventional squeeze film dampers, however, are nonlinear elements - the stiffness and damping they provide vary with vibrational amplitude. Thus a damper designed for normal levels of shaft unbalance may be completely unsultable for higher unbalance levels such as occur when a turbine blade is lost. In some cases of high unbalance, performance may degrade to that of a rigidly supported shaft, with possible catastrophic results as vibration amplitude exceeds available clearances and causes bearings to be overloaded.

The ideal damper is one that is linear - the stiffness and damping coefficients do not change with vibration amplitude. One such design is the curved beam damper (refs. 1 and 2). In theory, this damper should be completely linear. A possible disadvantage is that damping effectiveness could be largely lost if any air is introduced into the damper fluld.

The quasi-linear range of a conventional squeeze film can be enlarged by increasing the damper clearance. This has the disadvantage of requiring the damper to be longer. Furthermore, the added clearance results in less precise radial location of the rotor, possibly allowing rubbing of seal surfaces at engine startup and shutdown. Centering springs (e.g.. squirrel cage) are sometimes used in conjunction with squeeze flim dampers. The stiffness of these springs is chosen for rotordynamic purposes, however, and is frequently too low for purposes of shaft centerline location. These disadvantages of the conventional squeeze film can be somewhat mitigated by the multiple-shim damper (ref. 3), but the total clearance required may st 111 be larger than desirable. 
This paper introduces the dual-film damper. Under normal operating conditions it functions exactly like a conventional squeeze film damper, using only one of its oil films. When the unbalance reaches abusive levels, as may occur with a blade loss or foreign object damage, the second, larger-clearance film becomes active, controlling vibration amplitudes in a near-optimum manner until the engine can be safely shut down and repaired.

\title{
NOMENCLATURE
}

\author{
B damping coefficient \\ C damper radial clearance \\ e journal displacement relative to its bearing \\ $K$ damper stiffness coefficient \\ $\mathrm{L}$ damper length \\ $R$ damper radius \\ E damper eccentricity ratio, e/C \\ $\mu \quad$ fluid viscosity
}

\section{SQUEEZE FILM DAMPER CHARACTERISTICS}

A conventional squeeze fllm damper is shown in figure 1 . Within the limits of its capability, it effectively controls shaft vibration and bearing loads. For an open-end damper with a fully-cavitated ( $\pi$ ) film, the stiffness and damping coefficients are conveniently determined through the short bearing approximation. From (ref. 1):

$$
K=\frac{2 \mu R L^{3} \omega \varepsilon}{c^{3}\left(1-\varepsilon^{2}\right)^{2}} \quad B=\frac{\pi \mu R L^{3}}{2 c^{3}\left(1-\varepsilon^{2}\right)^{3 / 2}}
$$

It is apparent from these expressions that, for small eccentricities, stiffness increases approximately linearly with $\varepsilon$ and damping is approximately constant. For eccentricity ratios greater than about one-half, however, the $\left(1-\varepsilon^{2}\right)$ term in the denominator of both expressions means that stiffness and damping now increase more rapidly as eccentricity increases. Theoretically, they increase without 1 imit as $c$ approaches 1 . It is this nonlinear property which is responsible for the undesirable characteristics of squeeze film damped rotors at high unbalance loads.

Example of damped rotor behavior. - A multimass rotor which dynamically simulates a small gas turbine engine is shown as figure 2 . In reference 4 , squeeze film damper supports were designed for this rotor. The dampers were sized to handle a distributed unbalance of up to $29 \mathrm{~g} \mathrm{~cm}(0.4 \mathrm{oz}$ in.) for operation between the first and second critical speeds. For this level of unbalance the vibration amplitude at the center disk of the rotor is shown as the bottom curve of figure 3. Amplitude is very well controlled, and is, in 
fact, nearly identical to what would be obtained with the optimum stiffness and damping coefficlents derived in reference 4 .

The rotating load on the bearings due to the $29 \mathrm{~g} \mathrm{~cm}$ unbalance is plotted as the bottom curve of figure 4. Again, the results are very similar to those obtained with optimum constant damping and stiffness. The very low load near $10000 \mathrm{rpm}$ occurs because a nodal point in the rotor mode shape is very near the bearings at that speed.

When the unbalance is increased to $72 \mathrm{~g} \mathrm{~cm}$ ( 1 oz in.), the behavior changes markedly. There is now a large peak near $8000 \mathrm{rpm}$ in both vibration amplitude and bearing load. This speed is the first critical speed of the rotor when the bearings are rigidly supported. The amplitude peak which was prominent near $10000 \mathrm{rpm}$ for the $29 \mathrm{~g} \mathrm{~cm}$ unbalance is now almost completely masked.

If the unbalance is further increased to $290 \mathrm{~g} \mathrm{~cm}(4 \mathrm{oz} \mathrm{in.}$ ), amplitudes and bearing loads also increase further, but the character of the response changes little from that at $72 \mathrm{~g} \mathrm{~cm}$ unbalance. The damper is nearly bottomed and is almost completely. ineffective in controlling vibration. This is evidenced by the response curves being nearly coincident with those for rigidly supported bearings, shown as dashed curves in figures 3 and 4 .

The maximum vibration calculated over the speed range from 0 to 14000 $\mathrm{rpm}$ is plotted in figure 5 as a function of the rotor unbalance. The response has been normalized by dividing by the amount of unbalance to obtain a sensitivity factor.

Up to an unbalance of $29 \mathrm{~g} \mathrm{~cm}$, the sensitivity of the squeeze-film supported rotor is very close to that calculated for optimized constant stiffness and damping coefficients. (This optimum does not change with unbalance.) From about 29 to $43 \mathrm{~g} \mathrm{~cm}(0.6 \mathrm{oz}$ in.), two stable solutions exist to the rotordynamic equations of motion. In this bistable region, the rotor can operate stably at either of two conditions - high or low amplitude. It is sometimes possible to accelerate the rotor through the rigid-support critical speed and operate at low amplitude. If, however, the rotor is disturbed by an outside force, it may "jump up" to the high amplitude solution. Such jump phenomena have been observed experimentally in references 5 and 6 .

Above an unbalance of $43 \mathrm{~g} \mathrm{~cm}$ and near the critical speed the high amplitude response is the only solution. Both amplitude and bearing load are very nearly as high as for rigidly supported bearings. Amplitudes and loads approaching these predicted values would obviously prove catastrophic to the machine involved.

\section{DUAL CLEARANCE DAMPER}

The dual-clearance damper was designed in order to (1) maintain close control of rotor radial location during normal operation when the rotor is well balanced; (2) maintain control of vibration amplitude and bearing load during operation above the critical speed with high unbalance; and (3) allow safe deceleration through the critical speed with high unbalance. Figure 6 
11lustrates the concept. It consists of two squeeze f1lm dampers operating in series. During normal operation, the sleeve separating the two damper films is fixed in place by two or more shear pins. Only the inner film is active; behavior is then identical to that of the single-film damper of figure 1 . The clearance is only as high as is required for the rotor unbalance likely to occur in normal operation; thus the rotor radial location can be closely controlled. In the event of rotor blade loss or some other occurance which increases the unbalance, the damper load rises until the strength of the shear pins is exceeded. The pins shear, allowing the sleeve to move, and activating the outer damper film. The two films then operate in series; that is, the bearing load is transmitted first through the inner film; then through the sleeve and outer film to the machine structure. The outer film will generally have a larger clearance than the inner film in order to accommodate the larger amplitude of motion necessarily accompanying the higher unbalance. The inner and outer dampers will continue to operate together until the unbalance is corrected and new shear pins installed. 011 supply passages are not shown in figure 6; however, oll is typically supplied through a feed hole in the outer side of the outer film. The inner: damper receives its oll from the outer damper via a feed hole in the sleeve. The outer damper shown is of closed-end design. It was found when working out the design example to be discussed below that a shorter length for the damper would suffice than for an open-end damper.

\section{DESIGN EXAMPLE}

For the purpose of an example, a damper was designed for the rotor of reference 4 . This rotor, as 111 ustrated in figure 2 , consists of five concentrated masses on a slender shaft. The rotor is supported in ball bearings which are in turn supported by suitably designed dampers. The rotor was assumed to be operating with $290 \mathrm{~g} \mathrm{~cm}$ of unbalance; this is ten times the unbalance that was assumed for the design of the damper in reference 4 . The design procedure is similar to that of reference 4 . That is, the optimum support stiffness and damping determined in that work were duplicated insofar as feasible at the first rigid-support critical speed of $8280 \mathrm{rpm}$. The optimum stiffness and damping for each of the two bearing supports are

$$
\begin{aligned}
& K=0.91 \mathrm{MN} / \mathrm{m}(5150 \mathrm{lb} / \mathrm{in} .) \\
& B=1050 \text { to } 1470 \mathrm{Ns} / \mathrm{m}(6 \text { to } 8.4 \mathrm{lb} \mathrm{sec} / \mathrm{in} .)
\end{aligned}
$$

It has also been assumed, as in reference 4, that the bearing supports (comprising the ball bearing and inner damper journal) each have a mass of $1.2 \mathrm{~kg}$ $(2.7 \mathrm{lb})$, which was determined in reference 4 to be half of the first modal mass of the rotor. Thus the ratio of total support mass to rotor modal mass is one. Turbine oil with a viscosity of $11.9 \mathrm{mN} \mathrm{s} / \mathrm{m}^{2}\left(1.73 \times 10^{-6} \mathrm{Ib}\right.$ $\mathrm{sec} / \mathrm{in}^{2}$ ) is available to the damper.

For normal operation, with a distributed unbalance of no more than $29 \mathrm{~g}$ $\mathrm{cm}$, the damper design of reference 4 has been shown to be near optimum. Therefore this design will be used unchanged for the inner damper. It consists of an open end damper with a central feed groove; dimensions are summarized as follows: 

Journal diameter
$39.6 \mathrm{~mm}$
$(1.56$ in.)
Total working length
$11.4 \mathrm{~mm}$
$(0.45$ in.)
Radial clearance
$0.13 \mathrm{~mm}$
$(0.005$ in. $)$

In addition, there is a centering spring, operating in parallel with the damper, having a stiffness of $235 \mathrm{kN} / \mathrm{m}$ (1290 lb/in.).

The damper amplitude at the rigid support critical speed of $8280 \mathrm{rpm}$ with $290 \mathrm{~g} \mathrm{~cm}$ unbalance was determined from a rotor response code to be $0.45 \mathrm{~mm}$ (0.018 in.) for the optimum stiffness and damping of $0.91 \mathrm{MN} / \mathrm{m}$ and $1470 \mathrm{~N} \mathrm{~s} / \mathrm{m}$, respectively. A workable damper design must allow for this much motion if rotor amplitude and bearing load are to be minimized. Common practice is to set damper clearance at 2 or $21 / 2$ times the maximum anticipated amplitude; thus $c<0.5$, and the highly nonlinear range of the damper is largely avoided. This clearance is a compromise between two conflicting requirements. From the standpoint of avoiding high-eccentricity operation, a large damper clearance is desirable. However, a large clearance also requires the damper radius or length to be large, as can be seen from equations 1 . This makes it desirable to minimize the clearance so that overall damper dimensions are reasonable.

The clearance of the outer damper was provisionally set at $0.76 \mathrm{~mm}$ ( 0.030 in.); this clearance, when added to that of the inner damper, is slightly under twice the expected damper amplitude. Both open end and closed end designs were evaluated. The procedures are nearly identical; only that for the closed end design will be described, as that was the design adopted.

For a cavitated closed end damper, stiffness and damping, from reference 1, are:

$$
K=\frac{24 \mu R^{3} L \omega \varepsilon}{c^{3}\left(2+\varepsilon^{2}\right)\left(1-\varepsilon^{2}\right)} \quad B=\frac{12 \pi \mu R^{3} L}{c^{3}\left(2+\varepsilon^{2}\right)\left(1-\varepsilon^{2}\right)^{1 / 2}}
$$

The outer and inner dampers are in series; thus the effective stiffness and damping of the combination were determined by an iteration scheme having total damper amplitude as its input. The guiding principle was that the force developed by the outer damper must be equal to and colinear with that developed by the inner damper. The outer and inner dampers have different clearances, and in the present example are different types (closed and open end, respectively). Therefore, although the forces must be equal and collinear, the displacements are not. For either damper, total force developed is given by

$$
F^{2}=(K e)^{2}+(B e \omega)^{2}
$$

where $e, K$, and $B$ are the amplitude, stiffness, and damping for the particular damper (1.e., eq. (1) for the inner damper and eq. (2) for the outer damper). The mass of the sleeve was neglected.

For preliminary design purposes, a program was written for a desktop computer to carry out the iteration mentioned above. After several trials, outer damper dimensions were determined which yielded an overall damping coefficlent of the optimum value, $1470 \mathrm{Ns} / \mathrm{m}$, at a damper amplitude of $0.45 \mathrm{~mm}$ and precession rate of $8280 / \mathrm{min}$. Fortuitously, stiffness was also near optimum. 
The damper dimensions thus determined were then used as input to a rotor response code. This code was originally written for fixed values of support stiffness and damping (ref. 7). It was subsequently modified for the work of reference 4 to handle single-film squeeze dampers; the method used is similar to that of reference 8 . For the present work the iteration scheme for series dampers was incorporated.

The rotordynamics analysis showed that for $290 \mathrm{~g} \mathrm{~cm}$ unbalance, $0.76 \mathrm{~mm}$ clearance, and outer damper dimensions as determined above, bistabie operation was possible near the rigid-support critical speed. This is similar to what was found for the single-film damper for unbalance above $29 \mathrm{~g} \mathrm{~cm}$. This bistable region could not be eliminated without substantially enlarging the outer damper clearance. A modest increase in stiffness and damping coefficients ( 50 percent), however, reduced the bistable region to a speed band of only $250 \mathrm{rpm}$, or 3 percent of the critical speed. This was considered acceptable, as the rotor is expected to be in this speed band only when decelerating from running speed. It will pass through the band in a few revolutions; amplitude consequently cannot build up to the high values predicted by steady state analysis.

Outer damper dimensions determined are:

$$
\begin{aligned}
& R=51 \mathrm{~mm}(2 \mathrm{in.}) \\
& L=41 \mathrm{~mm}(1.63 \mathrm{in.}) \\
& C=0.76 \mathrm{~mm}(0.030 \mathrm{in.})
\end{aligned}
$$

An open end outer damper was also investigated. It required a considerably greater length, and thus is not as practical as the closed end design.

\section{DUAL DAMPER PERFORMANCE}

Figure 7 shows the amplitude of the rotor center disk as a function of speed for unbalance of $290 \mathrm{~g} \mathrm{~cm}$. For comparison, amplitude for a rotor with optimum (fixed) stiffness and damping coefficients is also shown. It is apparent that the dual damper compares very well with the theoretical constantcoefficient damper. Maximum rotor amplitude, though seemingly high at $1.4 \mathrm{~mm}$ ( 0.056 in.), is very nearly the lowest that can be attained with any damper. and less than 5 percent of the amplitude predicted for the single-film-damped rotor (see fig. 3). Bearing load is shown in figure 8. Maximum load for the dual-film damper is somewhat higher than that for the optimum constantcoefficient damper. This occurs because the dual-film damper was intentionally made stiffer to reduce the probability of high amplitudes accompanying bistable operation. A comparison with figure 4 shows that maximum bearing load is less than 2 percent of the maximum predicted for the single-film damper.

The sensitivity of the dual-film damped rotor over a range of unbalance levels is shown in figure 5 . The sensitivity is close to the optimum over the entire range, and only slightly higher than for the single-film damper at low unbalance levels. 


\section{CONCLUDING REMARKS}

A dual-clearance squeeze film damper has been described. This damper offers the same good performance as conventional single-film dampers at normal unbalance levels. When unbalance.rises because of blade loss or other abnormal conditions, the dual-film damper, unlike the single-film damper, is still able to effectively damp vibration and prevent destructive rotor amplitudes and bearing loads.

\section{REFERENCES}

1. Bhat, S. T., Buono, D. F., and Hibner, D. H., "Analys is of High Load Dampers," PWA-5779-10, Pratt a Whitney Aircraft Group, East Hartford. Conn., Aug. 1981. (NASA CR-165503).

2. Taylor, D. L., and Fehr, V. S., "Analysis and Design of Segmented Dampers for Rotor Dynamic Control," ASME Journal of Lubrication Technology. Vol. 104, No. 1, Jan. 1982, pp 84-90.

3. Monze1, F. J., and Bobo, M., "Bearing Assembly with Multiple Squeeze Film Damper Appartus," United States Patent No. 4,214,796, July 1980.

4. Cunningham, R. E., Fleming, D. P., and Gunter, E. J., "Design of a Squeeze-Film Damper for a Multi-Mass Flexible Rotor," ASME Journal of Engineering for Industry. Vol. 97, No. 4, Nov. 1975, pp. 1383-1389.

5. Simandiri, S., and Hahn, E. J!., "Experimental Evaluation of the Predicted Behavior of Squeeze-Film-Bearing-Supported Rigid Rotors " Journal of Mechanical Engineering Science, Vol. 21, No. 6, Dec. 1979, Pp. 439-451.

6. Botman, M., and Samaha, M. A., "Experiments on the Dynamic Behavior of a Supercritical Rotor," ASME Journal of Mechanical Destgn, Vol. 104, No. 2. Apr. 1982, pp. 364-369.

7. Kirk, R. G., and Gunter, E. J., "Nonlinear Transient Analys is of Multi-Mass Flexible Rotors - Vol. 2 Appendices and Computer Programs. Report No. ME-4040-112-72U, Univ. of Virginia, Charlottesville, Va.. June 1972 .

8. Greenhill, L. M., and Nelson, H. D., "Iterative Determination of Squeeze Film Damper Eccentricity for Flexibie Rotor Systems," ASME Journal of Mechanical Design, Vol. 104, No. 2, Apr. 1982, pp. 334-338. 


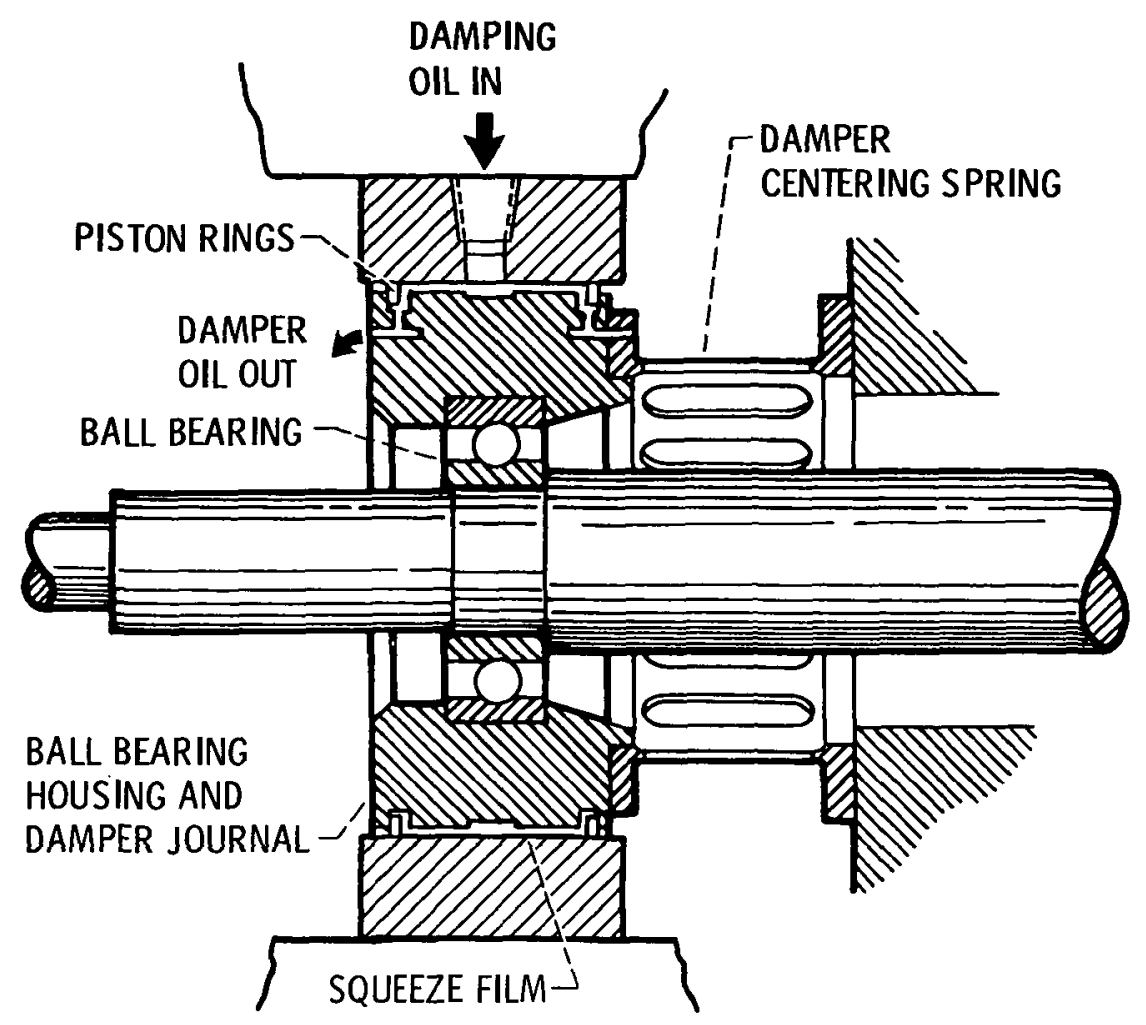

Figure $1_{\text {。 }}$ - Typical squeeze film damper.

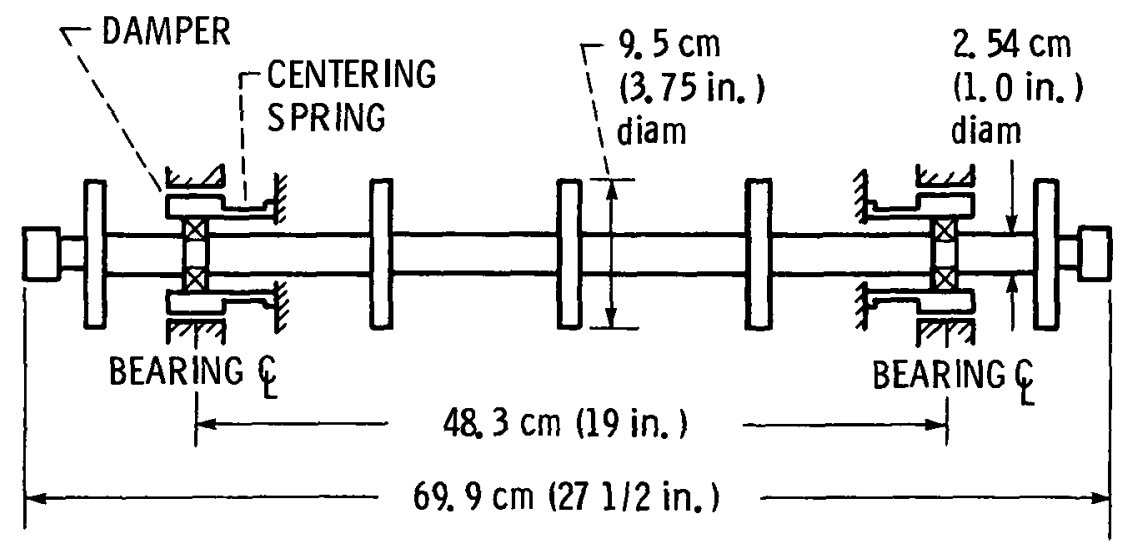

Figure 2. - Five mass flexible rotor. 


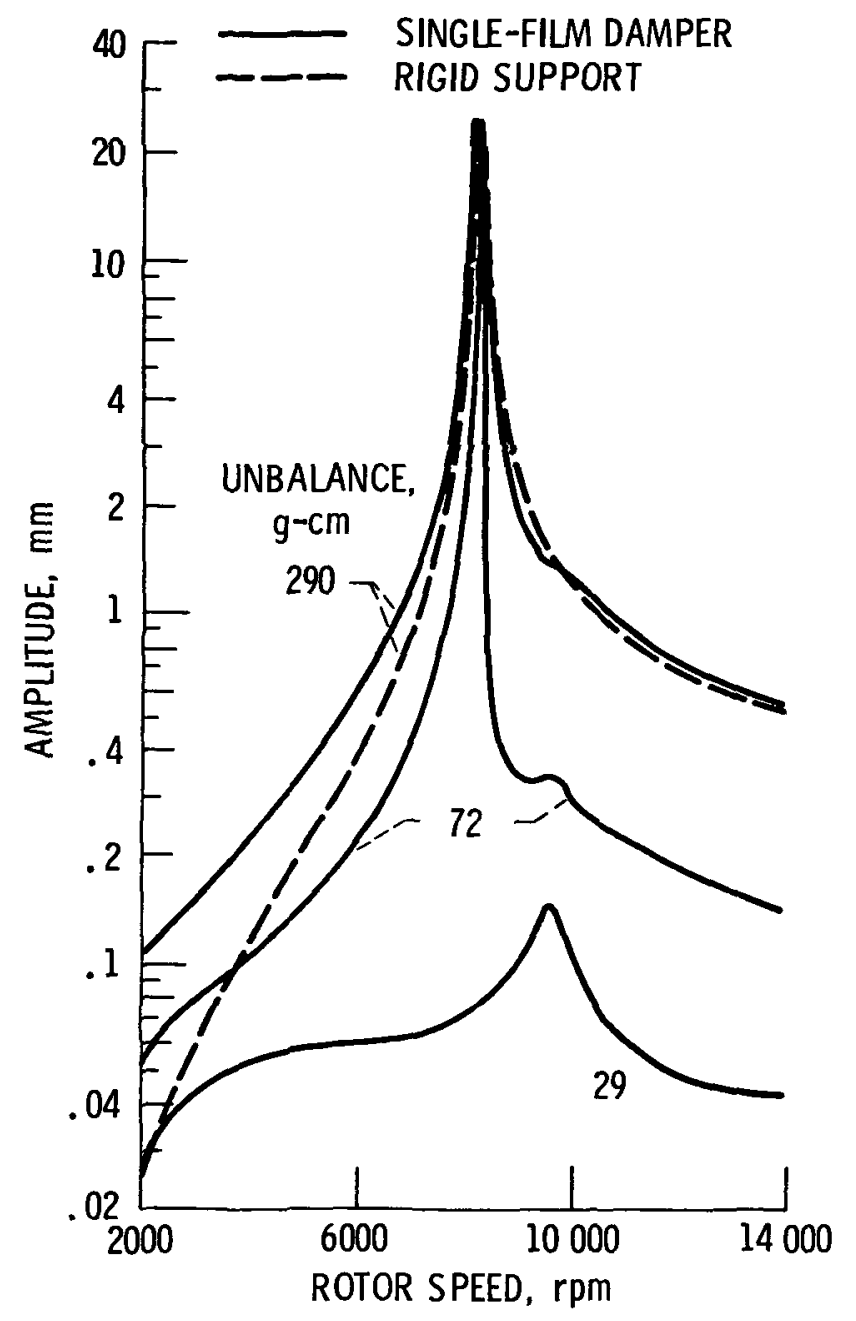

Figure 3. - Rotor midspan amplitude; singlefilm damper or rigid support. 


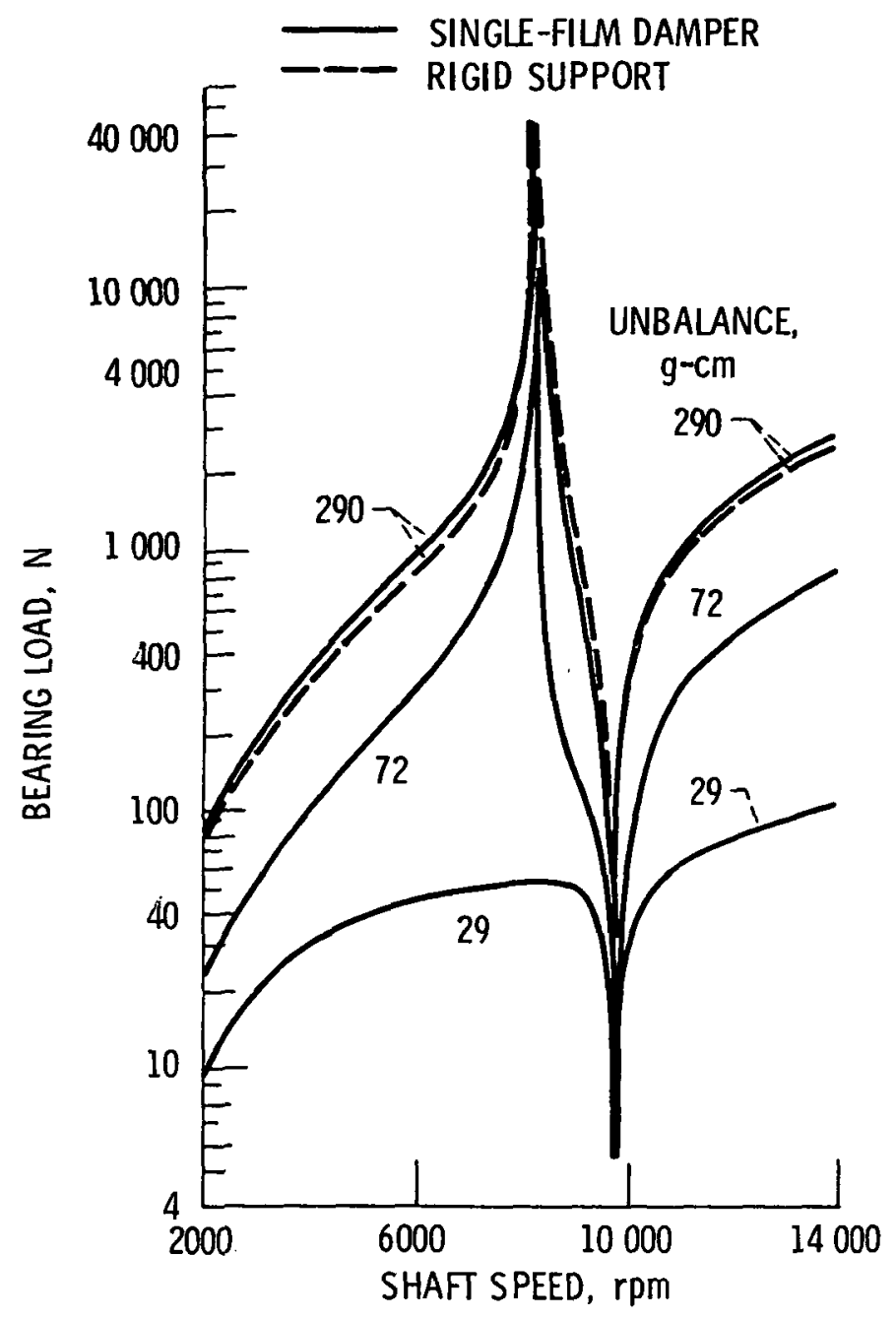

Figure 4. - Bearing load with single-film damper or rigid support. 

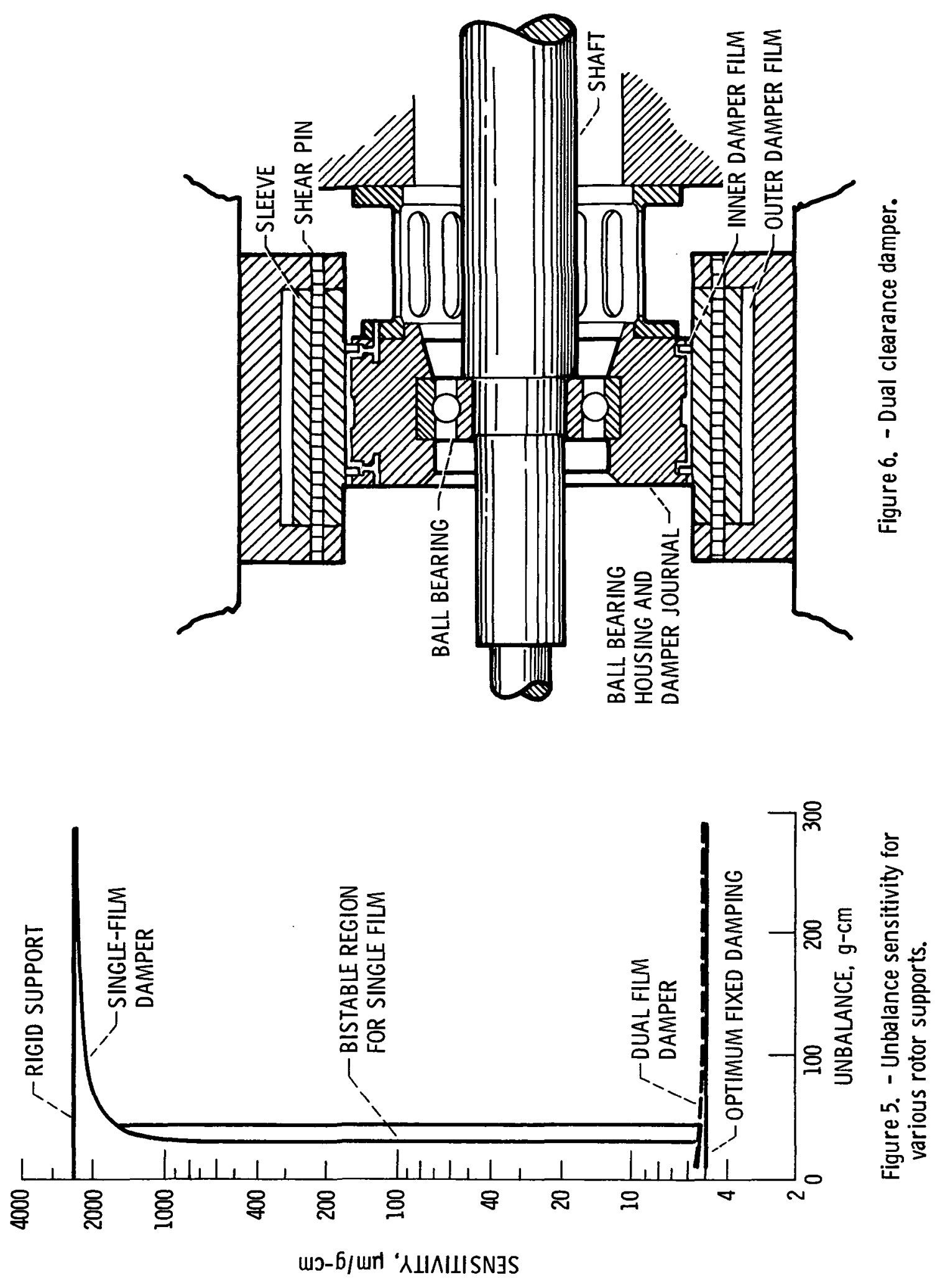


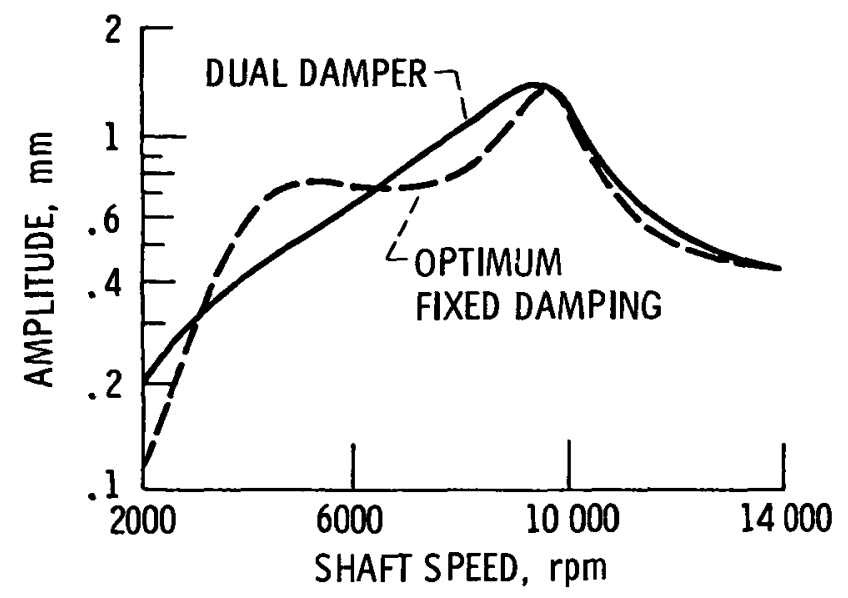

Figure 7. - Rotor midspan amplitude; unbalance $290 \mathrm{~g}-\mathrm{cm}$.

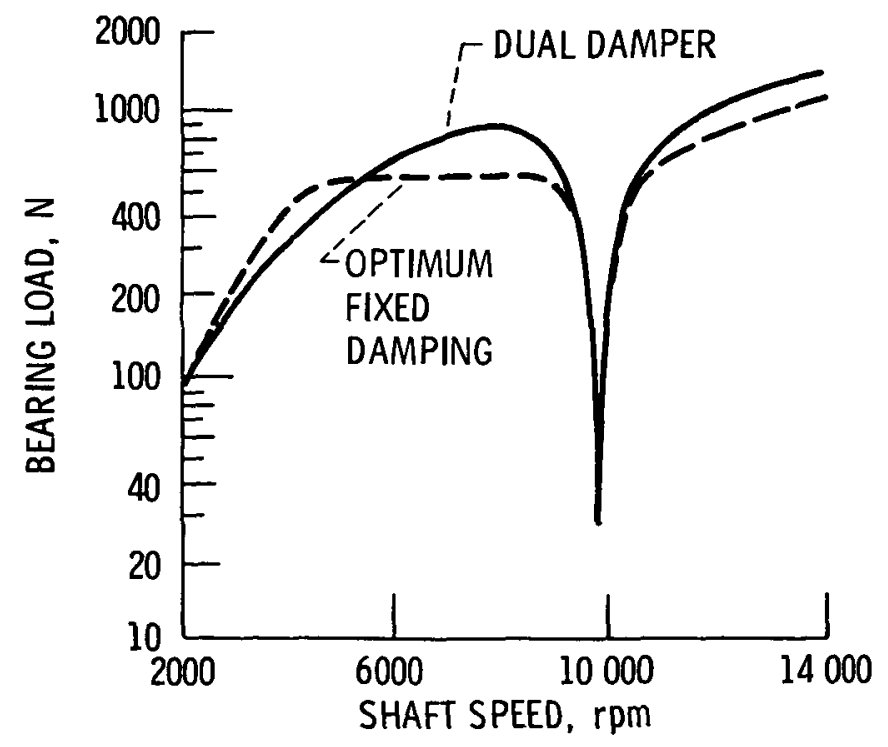

Figure 8 - Bearing loads with dual film damper and optimum fixed damping; unbalance $290 \mathrm{~g}-\mathrm{cm}$. 


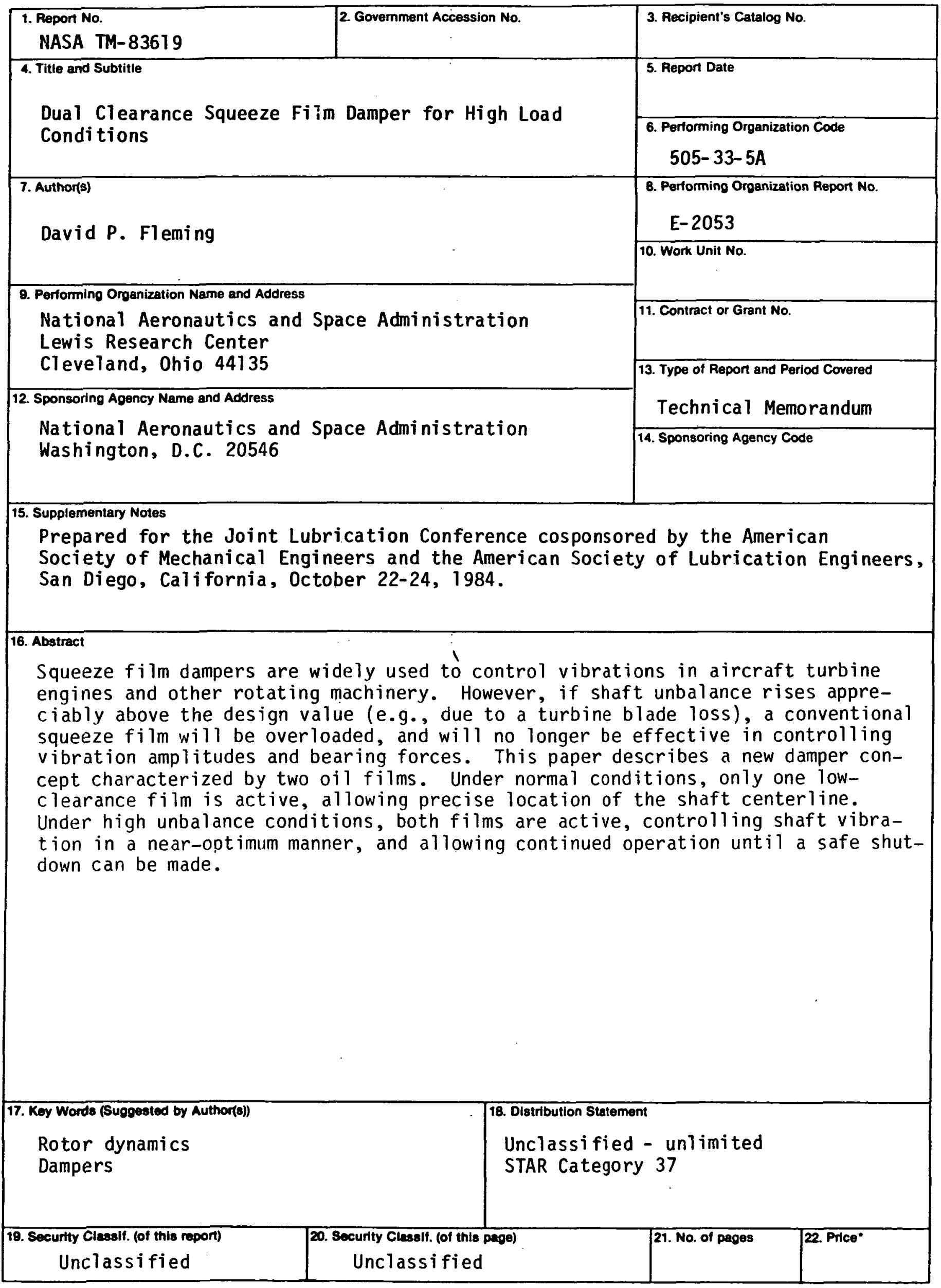

-For sale by the National Technical Information Service, Springfield, Virginia 22161 
National Aeronautics and Sppce Administration

Washington, D.C.

20546

Official Busines:

Penalty for Private Use. $\$ 300$

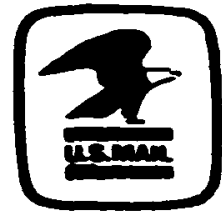

Poctes and Fees Paid Mrtional Aeronzuties and Spece Administrotion Masn-451 